\title{
O caminho das orientações da UNESCO para proteção do direito à infância no Brasil a partir da década de 1990
}

\section{The path of UNESCO's guidelines for protection of the right to childhood in Brazil from the 1990s}

\author{
Maria Aparecida Cecílio ${ }^{1}$ \\ Elias Canuto Brandão ${ }^{2}$
}

\begin{abstract}
RESUMO
Apresentamos resultado de pesquisa realizada entre 2007 e 2011 sobre as "Características das orientações da UNESCO para proteção do direito à infância nas políticas do Estado brasileiro a partir de 1990". O objeto de análise são as orientações da Organização das Nações Unidas para a Educação, a Ciência e a Cultura (UNESCO) para proteção ao direito à infância no objetivo de identificar as contradições nas políticas de garantia do direito à infância. No período de 1980 a 2011, o alcance da UNESCO encontra-se implícito na apropriação dos Estados Nacionais no discurso da paz mundial, justificativa de fortalecimento do terceiro setor e, na ação de governo, no reconhecimento legal das orientações e julgamentos internacionais dos tratados ratificados pelo Brasil. Abordarmos as contradições políticas com o conceito de "trabalho decente", nas políticas de erradicação do trabalho precoce pós Decreto Federal no 3.597, de 12 de setembro de 2000, por constituir políticas voltadas à infância no meio rural.
\end{abstract}

Palavras-chave: políticas educacionais; UNESCO; direito à infância.

ABSTRACT

1 Universidade Estadual de Maringá, Maringá, Paraná, Brasil. Av. Colombo nº 5790 - Jardim Universitário. CEP: 87020-900.

2 Universidade Estadual do Paraná, Curitiba, Paraná, Brasil. Av. Pref. Lothário Meissner, nº 350 - Jardim Botânico. CEP: 80210-170. 
We present the results of a research conducted between 2007/2011 on the "characteristics of the UNESCO guidelines for protection of the right to childhood in the Brazilian state policies since 1990". The objects of analysis are UNESCO's guidelines to protect the right to childhood in order to identify the contradictions in said policies to guarantee the right to childhood. From 1980 to 2011, the reach of UNESCO is implicit in the appropriation of the National States in the world peace discourse, the justification for strengthening the third sector and, in government action, the legal recognition of judgments and guidelines of international treaties ratified by Brazil. We approach the political contradictions based on the concept of "decent work", in the early-labor eradication policies after Fed Dec. No.3597 of September 12,2000 , for its policies to provide children in rural areas.

Keywords: educational policies; UNESCO; the right to childhood.

São direitos sociais a educação, a saúde, o trabalho, o lazer, a segurança, a previdência social, a proteção à maternidade e à infância, a assistência aos desamparados, na forma desta constituição (BRASIL, 1988, art. $6^{\circ}$ ).

O presente artigo resultou de pesquisa realizada no período de 2007 a 2011. Constitui-se das temáticas debatidas em protocolos de leituras, da produção bibliográfica resultante deste processo de estudo e sua inserção no ensino de graduação e de pós-graduação stricto sensu na Universidade Estadual de Maringá (UEM) - PR, Brasil.

As leituras realizadas no período convergiram para investigação sobre as "Características das orientações da UNESCO para proteção do direito à infância presentes nas políticas do Estado brasileiro a partir de 1990". $\mathrm{O}$ encaminhamento metodológico da leitura investigativa definiu a pauta de observações genéricas no referente à categoria de análise, contradição passa a compor a fonte de visão específica para as demandas pontuais de identificação dos problemas, das estratégias de solução governamental, da localização temporal e de contextualização dos espaços territoriais das ações políticas dos diferentes agentes do poder no Brasil no referido período.

Elegemos como objeto de análise as orientações da UNESCO para proteção ao direito à infância presentes nas políticas brasileiras no objetivo de identificar as contradições nas políticas de garantia do direito à infância à medida de sua planificação e execução em âmbito nacional ou dos Estados confederados por serem essas políticas afetas a processos de avaliação generalizantes quanto aos resultados. 
Os propósitos e funções da Constituição da UNESCO dispostos em seu artigo I delimitaram o campo de investigação documental e constituiu pressupostos de características das políticas do Estado brasileiro no processo de erradicação do trabalho precoce e penoso exercido no meio rural brasileiro, como forma de proteção ao direito à infância.

Foram propósitos da UNESCO:

[...] contribuir para a paz e para a segurança, promovendo colaboração entre as nações através da educação, da ciência e da cultura [...] (a) Colaborar no trabalho de fazer avançar o conhecimento e o entendimento mútuos entre os povos, através de todos os meios de comunicação de massa, e com esse objetivo recomendar aqueles acordos internacionais que possam ser necessários para promover o livre fluxo de idéias, através da palavra e da imagem; (b) Oferecer impulso renovado à educação popular e disseminação da cultura: Colaborando com os Membros, mediante solicitação deles, no desenvolvimento de atividades educacionais; Instituindo a colaboração entre as nações para fazer avançar o ideal da igualdade de oportunidades educacionais [...]; Sugerindo os métodos educacionais mais adequados à preparação das crianças do mundo para as responsabilidades da liberdade; (c) Manter, expandir e difundir o conhecimento: Garantindo a conservação e a proteção do legado mundial de livros, obras de arte e monumentos de história e de ciência, recomendando as convenções internacionais necessárias às nações envolvidas; Estimulando a cooperação entre as nações em todos os ramos de atividade intelectual, incluindo o intercâmbio internacional de pessoas ativas nos campos da educação, da ciência e da cultura, além do intercâmbio de publicações, objetos de interesse artístico e científico, bem como outros materiais de informação; Desencadeando métodos de cooperação internacional calculados para dar aos povos de todos os países acesso a material impresso e publicado, produzido por qualquer um deles. [...] preservação da independência, da integridade e da diversidade frutífera das culturas e dos sistemas educacionais dos Estados Membros da Organização, fica a ela vedada a intervenção nas questões essencialmente restritas à jurisdição interna desses Estados (UNESCO, 2002, p. 2 e 3).

Iniciando a investigação das recomendações a partir da Constituição da UNESCO, aprovadas em 1945, retornam à materialidade das políticas por meio dos atos de governo que precederam a Constituição Federal do Brasil, de 1988, em relação aos compromissos internacionais de Estado. Constatamos que nas 
considerações gerais sobre as realizações na área de educação no meio rural brasileiro, no documento elaborado pelo Ministério da Educação (MEC), para servir de subsídio à Delegação Brasileira junto à XXI Sessão da Conferência Geral da UNESCO, realizada em Belgrado, no período de 22 de setembro a 28 de outubro de 1980. O documento registrava as ações políticas de o Governo Militar no campo educacional, como referência de atendimento às recomendações para o desenvolvimento econômico, justificado no II Plano Nacional de Desenvolvimento (1975-1979) (II PND) e nos objetivos e diretrizes da ação governamental.

O Plano estabelecia bases para os programas específicos no meio rural. Previa a criação de condições para seu desenvolvimento, com a ação de diversos setores, para pretensas profundas transformações no meio rural. Em síntese, o documento apresentava o seguinte texto:

A política educacional de atendimento às áreas rurais vinha se efetivando de várias formas, dentre as quais se destacam: a elaboração de diretrizes curriculares para o ensino de $1^{\circ}$ grau; a realização de programas de alfabetização e de educação continuada; a construção e instalação de estabelecimentos de ensino agropecuário; a capacitação de professores leigos; o apoio técnico e financeiro às instituições que atuam nesse meio; os programas de extensão universitária visando à aproximação entre a universidade e sua realidade regional; os programas de alimentação escolar; a distribuição de material escolar; a realização de estudos e pesquisas sobre a educação no meio rural (BRASIL, 1980, p. 3).

O estudo realizado demonstra que no período entre 1980 e 2011, o alcance das influências da UNESCO encontrava-se implícito na apropriação dos Estados Nacionais, entre os quais destacamos o Brasil, no discurso da paz mundial, na justificativa de fortalecimento do terceiro setor ${ }^{3}$ e na ação de governo. Isto tornou-se implícito em relação ao reconhecimento legal das orientações e julgamentos internacionais dos tratados ratificados pelo Estado brasileiro, por meio de emenda constitucional ao art. $5^{\circ}$, do texto de lei da Carta Magna de 1988 , em seu inciso $78, \S 3^{\circ}$, incluso pela emenda constitucional de número 45 de 2004, com o seguinte texto:

Os tratados e convenções internacionais sobre direitos humanos que forem aprovados, em cada Casa do Congresso Nacional, em dois turnos,

3 Disponível em AVINA e BID: <http://www.indicedoadores.org/ladid_search>. 
por três quintos dos votos dos respectivos membros, serão equivalentes às emendas constitucionais (BRASIL, 1988, art. $5^{\circ}$, inc. LXXVIII, $\S 3^{\circ}$ ).

Em seguida, no art. $6^{\circ}$, Capítulo II - Dos Direito Sociais, a proteção à maternidade e à infância é destacada como um dos ícones destes direitos. $\mathrm{O}$ art. 22, inciso XV, que estabelece competência privativa de a União legislar sobre a "proteção à infância e à juventude", o que precede ao Estatuto da Criança e do Adolescente (ECA) ${ }^{4}$, lei esta dedicada aos direitos e deveres da criança e do adolescente sob a perspectiva de construção de uma doutrina de proteção integral.

Decorrente desse ato legal de reconhecimento da importância da infância no texto constitucional, a questão polêmica que passamos a abordar remete-se ao conceito de "trabalho decente", norteador das políticas de erradicação do trabalho precoce no Brasil pós Decreto Federal n $\mathrm{n}^{\mathrm{0}}$ 3.597, de 12 de setembro de 2000, por nortear o debate sobre a proteção do direito à infância no Brasil, à medida de seu significado na orientação de políticas voltadas à infância no meio rural.

O entendimento da presença de orientações da UNESCO nas políticas de proteção ao direito à infância no Brasil a partir da década de 1990 nos possibilitou uma investigação das generalidades das orientações desenvolvidas por esta agência ou com sua participação por meio de programas sociais e campanhas políticas e educativas.

As ações recomendadas com base em estudos pontuais promovidos pela UNESCO caracterizam a construção do discurso do desenvolvimento sustentável que se apresenta como finalidade das políticas a serem criadas pelos Estados, principalmente no trato de questões voltadas às áreas rurais para o controle da pobreza endêmica 5 .

Há nos relatórios de diagnóstico das condições de vida educacional no meio rural da UNESCO, por exemplo, a apresentação de comparação quantitativa de dados escolares, quando se quer demonstrar um quadro geral sobre o país, e uma análise qualitativa, quando a questão a ser abordada é a formação de professores e a melhoria das condições estruturais para oferta educacional.

Diante das generalidades da ação da UNESCO para a proteção do direito à infância no Brasil, analisamos sua presença e influência nas políticas de proteção a esse direito, pós 1990, considerando que, a partir de 1988, com o advento da Constituição Federal Democrática de Direitos, a legalidade das ações governamentais pode ser verificada e acompanhada, apesar da dificuldade de acesso aos instrumentos de avaliação de sua efetividade.

4 Cf. Brasil (1990).

5 Cf. Vasconcelos (2008). 
Entre 2007 e 2011, constatamos que as ações políticas nacionais limitaram-se aos planos governamentais por meio de programas temporários reduzidos às populações classificadas como de extrema pobreza ${ }^{6}$, no entanto, aglutinadas aos centros urbanos. A exemplo deste procedimento, temos o ProInfância ${ }^{7}$, conforme publicado no Portal do Fundo Nacional de Desenvolvimento da Educação (FNDE):

O programa foi instituído pela Resolução $\mathrm{n}^{\circ}$ 6, de 24 de abril de 2007 e é parte das ações do Plano de Desenvolvimento da Educação (PDE) do Ministério da Educação. Seu principal objetivo é prestar assistência financeira, em caráter suplementar, ao Distrito Federal e aos municípios que efetuaram o Termo de Adesão ao Plano de Metas Compromisso Todos pela Educação e elaboraram o Plano de Ações Articuladas (PAR). [...] Entre 2007 e 2008, o ProInfância investiu na construção de 1.021 escolas. [...] Em 2009, o programa superou a meta prevista de financiar a edificação de 500 unidades. Em 2010, foram celebrados convênios para a construção de 628 escolas de educação infantil. Para 2011, a previsão é de investir na edificação de 1.500 escolas, no âmbito da segunda etapa do Programa de Aceleração do Crescimento (PAC 2) (BRASIL, 2011).

Considerando que, do início dos anos de 1990 aos anos 2000, as ações políticas conformadas foram relatadas em números, retomamos os registros dos relatórios de atividades do $\mathrm{FNDE}^{8}$, no ano de 1997, toda criança na escola, demonstrando que o Brasil celebrou 414 convênios de transporte escolar com órgãos ou entidades federais, estaduais, municipais e organizações não governamentais.

No atendimento a crianças de 0 a 6 anos de idade, de um total de R\$ 22.829.549,00 (vinte dois milhões, oitocentos e vinte nove mil, quinhentos e quarenta e nove reais) foi gasto com a capacitação docente $6 \%$ (seis por centro), o equivalente a R \$1.398.880,00 (um milhão, trezentos e noventa e oito mil, oitocentos e oitenta reais), ou seja, menos de $10 \%$ do que foi investido em construção predial e equipamentos.

Consta no relatório do FNDE de 1998, que:

6 Cf. Coelho, Tapajós e Rodrigues (2010).

7 Cf. Brasil (2011).

8 O FNDE é uma autarquia federal criada pela Lei $n^{\circ} 5.537$, de 21 de novembro de 1968 , alterada pelo Decreto-Lei no 872 , de 15 de setembro de 1969, vinculada ao MEC. 
O Transporte do Escolar destacou-se este ano como um dos principais instrumentos para que milhares de crianças freqüentassem os bancos escolares, principalmente as moradoras da zona rural, contribuindo para que o Programa Toda Criança na Escola apresentasse resultados positivos. Registrou-se crescimento de $270 \%$ no repasse de recursos aos Municípios e incremento no número de Municípios atendidos (BRASIL, 1998a, p. 5).

No ano de 1998, celebrou-se 1.558 convênios de transporte escolar'. A partir de 1999, esta autarquia passou a funcionar como uma gerenciadora do orçamento público, mediante as dificuldades de controlar o gasto do dinheiro público em prol da infância, considerando o grande número e a diversidade de convênios celebrados no processo de descentralização das ações de atendimento à infância no campo educacional e, com destaque, para deslocamento de alunos da área rural para as cidades. Importa registrar que para as populações do campo o transporte escolar deveria ocorrer intracampo e não do campo para a cidade, permanecendo o Estado brasileiro com uma dívida social, política e educacional para com a população do campo, marginalizada no direito à educação onde residem e trabalham e com a qualidade necessária à formação integral do sujeito do campo desde a infância.

No Plano Plurianual (PPA) de $2002 / 2003^{10}$, com o condicionamento legal para elaboração do orçamento da União, foi inserido o FNDE, no propósito de realizar orientação estratégica ao Presidente da República para a execução de programas na área da educação.

Constatamos que "[...] Nas opções estratégicas definidas no PPA, identificam-se os macro-objetivos, dentre os quais destacam-se: 'Elevar o Nível Educacional da População e Ampliar a Capacitação Profissional' e 'Ofertar Escola de Qualidade Para Todos"”.

As estratégias descritas nos relatórios do FNDE nos apresentam a confirmação da insuficiência das políticas dos anos 1990 e 2000 na proteção do direito à infância via educação no Brasil, na medida, em sua maioria, da efetivação de políticas quantitativas, pontuais e praticadas por organizações não governamentais impossibilitando um processo avaliativo que responda às reais condições educacionais do país e, ao mesmo tempo, alimentando redes de atendimento formadas por organizações, que, em muitos casos, passaram a existir com a

9 Por mais convênios que tenham sido celebrados, continua tímido o avanço no âmbito da educação no campo, necessitando de estudos e investigações sobre os recursos públicos que pouco chegaram ao destino final: os estudantes.

10 Decreto $n^{\circ} 2.829$, de 1998, estabeleceu normas para a elaboração e execução do Plano Plurianual e dos Orçamentos da União. 
única finalidade de ser braço do Estado na educação, sem outras finalidades que justifiquem sua manutenção.

O crescimento do número de convênios para transporte das populações de crianças da zona rural para os centros urbanos é um demonstrativo da influência das organizações internacionais nas políticas de controle social dos países em desenvolvimento, que não representa força política de proteção à infância ao assumirem o caráter temporário e precário de atendimento, muitas vezes em função do cumprimento de metas quantitativas.

As organizações internacionais contribuíram com o norteamento das políticas de fechamento de escolas no campo, substituindo o direito ao estudo em escolas próximas de onde residem os trabalhadores camponeses pelo transporte das crianças e adolescentes para escolas urbanizadas. Na prática, as organizações internacionais promoveram fragilidades nas políticas de Estado e favoreceram a governança por meio de programas de caráter compensatório que não atendem às demandas das populações camponesas, principalmente na área educacional e favorecem o crescimento de organizações não governamentais que passam a fazer o que, por preceito constitucional, é dever do Estado.

Na medida de descentralização dos serviços, como o de transporte escolar e o de formação técnica para zona rural, desenvolvida a partir dos anos 1990, promoveu-se um barateamento dos custos com os estudantes da zona rural por meio de cursos curtos, sem comprovação de seus benefícios para a população pobre e muitos destes processos, desenvolvidos pelo Serviço Nacional de Aprendizagem Rural (SENAR) $)^{11}$, no atendimento às metas do milênio ${ }^{12}$, a saber:

1. Reduzir a pobreza

2. Atingir o ensino básico universal

3. Promover a igualdade entre os sexos e a autonomia das mulheres

4. Reduzir a mortalidade na infância

5. Melhorar a saúde materna

6. Combater a HIV/Aids, a malária e outras doenças

7. Garantir a sustentabilidade ambiental

8. Estabelecer uma Parceria Mundial para o Desenvolvimento (PNUD, 2012).

As reformas educacionais ocorridas a partir da década de 1990 acentuaram a dualidade presente na oferta educacional de modo que as populações pobres

11 Cf. SENAR (2011).

12 Cf. PNUD (2012). 
passaram a ver seus filhos subjugados à oferta de qualificação profissional realizada por organizações privadas conveniadas aos cofres públicos, sem garantia de qualidade e impossibilitadas de continuidade dos estudos.

As ações políticas de transferência de responsabilidades nos fizeram questionar a disposição constitucional do art. $6^{\circ}$, caracterizando a ação de proteção à infância como um direito social, logo, um direito reservado, subentendendo o atendimento às populações empobrecidas, dentre as quais, a população infantil das zonas rurais do Brasil. Este dispositivo margeia as ações governamentais delineadas para execução em conformidade com pleitos partidários limitados em quatro anos, ou seja, o período de um mandato eletivo, tendo resultado em interrupções de ações educacionais.

Evidenciam-se neste arcabouço, as possibilidades de criação de redes de organizações não governamentais que, subsidiadas por governos em nome do Estado, assumem a tarefa que seria de Estado - é a transferência de responsabilidades legais. Resulta da inoperância do Estado brasileiro em consolidar políticas públicas universais e o Plano Nacional pela Primeira Infância ${ }^{13}$, elaborado pela Rede Nacional Primeira Infância com ampla participação social, em maio de 2010, em Brasília, em cobrança aos compromissos assumidos pelo Brasil desde o Encontro Mundial de Cúpula pela Criança ${ }^{14}$ da Organização das Nações Unidas (ONU), em 30 de setembro de 1990, na cidade de Nova Iorque - EUA.

O plano é um documento político e técnico com ações previstas para o período de 2011 a 2022, estruturadas sobre questões basilares como a necessidade de garantia de nascimento, registro civil de nascimento e demais garantias constitucionais não atendidas pelo Estado brasileiro por meio de seus governos. O plano observa que "Viver a primeira infância com plenitude é um direito de toda criança cujo cumprimento depende da decisão, do compromisso político e ético e do persistente empenho do Governo" (BRASIL, 2010a, p. 8).

Identificamos, na presente análise, que as políticas de garantia do direito à infância são contraditórias por resumirem os planos de atendimento à pobreza endêmica e extrema, das populações das cidades, sinalizando a interpretação do caráter constitucional dado à proteção da infância. O que seria um direito universal a ser atendido por políticas públicas, resume-se em ações focalizadas.

A escola como símbolo de urbanidade, principalmente para educação infantil, é tratada, nas ações de governo, como objeto estratégico de controle da fome, da pobreza e da marginalidade. Essas características das políticas de atendimento educacional são generalizadas nas ações focalizadas de políticas de corte social e demográfico em atendimento às orientações das organizações

13 Cf. Rede Nacional Primeira Infância (2010).

14 Cf. ONU (1990). 
internacionais que controlam as políticas de governo dos países em desenvolvimento na medida em que suas orientações são absorvidas nas políticas nacionais.

São fator de análise as orientações da UNESCO nas políticas brasileiras no campo educacional, a valorização da avaliação das políticas por índices quantitativos em detrimento da avaliação mais criteriosa quanto à qualidade da oferta, manutenção e investimento na educação como um caminho de garantia de direitos.

Observamos que a expressão da contradição é caracterizada no formato da legalidade, que, no intento dos representantes do Estado de demonstrar ações de garantia de direito à infância, reafirmam a existência da violação sistêmica ao direito ao transferirem as responsabilidades de Estado às organizações do terceiro setor.

O Decreto presidencial $\mathrm{n}^{\mathrm{o}} 3.597$, de $2000^{15}$, materializou o cunho político da ação de governo que nortearia programas, campanhas e planos em todas as esferas do poder. As ações políticas vinculam-se às chamadas "piores formas de trabalho infantil". No art. 16 do referido decreto, temos os contornos da orientação destas políticas governamentais em nome do Estado, com roupagem de democracia participativa, como podemos constatar no art. 16, inc. III, da Aplicação, alínea 16, que estabelece:

Uma cooperação e/ou assistência internacional maior entre os Membros destinada a proibir e eliminar efetivamente as piores formas de trabalho infantil deveria complementar os esforços nacionais e poderia, segundo proceda, desenvolver-se e implementar-se em consulta com as organizações de empregadores e de trabalhadores. Essa cooperação e/ ou assistência internacional deveria incluir:

a) a mobilização de recursos para os programas nacionais ou internacionais;

b) a assistência jurídica mutua;

c) a assistência técnica, inclusive o intercâmbio de informações, e

d) o apoio ao desenvolvimento econômico e social, aos programas de erradicação da pobreza e à educação universal (BRASIL, 2010b, art. 16 , inc. III).

15 Promulga Convenção 182 e a Recomendação 190 da Organização Internacional do Trabalho (OIT) sobre a Proibição das Piores Formas de Trabalho Infantil e a Ação Imediata para sua Eliminação, concluídas em Genebra, em 17 de junho de 1999. Cf. Brasil (2010b). 
Considerando o pressuposto legal de que existe a pior forma de trabalho infantil, a contradição que se apresenta é a existência declarada e, porque não, reconhecida por parte do Estado Nacional brasileiro e da ONU de melhores formas de trabalho infantil, assim compreendida na conformação da existência de piores formas por meio de declaração da OIT.

Mesmo com o avanço do Brasil no início do III milênio para patamares de país desenvolvido, o trato à educação ainda é um gargalo a ser transposto e, no que tange à população trabalhadora que vive no campo, continua sendo um desafio político que os governos não têm dado conta de superar na totalidade, à exceção de algumas políticas de resultado oriundas da pressão dos movimentos sociais do campo, que se limita a políticas sociais temporárias por meio da criação de programas que sobrevivem com valores ínfimos para sua execução. É fato que essa realidade contribui para a existência da exploração da mão de obra precoce e penosa.

\section{REFERÊNCIAS}

AVINA; BANCO INTERAMERICANO DO DESENVOLVIMENTO (IDB). Índice de doadores para a América Latina. Disponível em: $<\mathrm{http} / /$ www.indicedoadores.org/ about>. Acesso em: 22/2/2012.

BRASIL. Lei no 5.537, de 21 de novembro de 1968. Cria o Instituto Nacional de Desenvolvimento da Educação e Pesquisa (INDEP), e dá outras providências. Diário Oficial da União, Brasília, DF, 22 nov. 1968.

. Decreto-Lei n ${ }^{\circ} 872$, de 15 de setembro de 1969. Complementa disposições da Lei número 5.537, de 21 de novembro de 1968, e dá outras providências. Diário Oficial da União, Brasília, DF, 16 set. 1969.

. II Plano Nacional de Desenvolvimento (1975-1979). Brasília, DF, 1974. Disponível em: < http://www.planalto.gov.br/ccivil_03/Leis/1970-1979/anexo/ANL6151-74. PDF>. Acesso em: 26/9/2013.

. Ministério da Educação. XXI Sessão da Conferência Geral da UNESCO. Belgrado, 22 set./28 out. 1980.

. Constituição (1988). Constituição da República Federativa do Brasil. Brasília, DF: Senado Federal, 1988. Disponível em: <http://www.planalto.gov.br/ccivil_03/ constituicao/ConstituicaoCompilado.htm>. Acesso em: 24/6/2011.

. Lei no 8.069, de 13 de julho de 1990. Dispõe sobre o Estatuto da Criança e do Adolescente e dá outras providências. Diário Oficial da União, Brasília, DF, 16 jul. 
1990. Disponível em: <http://www.planalto.gov.br/ccivil_03/leis/L8069.htm>. Acesso em: 22/2/2012.

. Decreto n ${ }^{\circ} 2.829$, de 29 de outubro de 1998. Estabelece normas para a elaboração e execução do Plano Plurianual e dos Orçamentos da União e dá outras providências. Diário Oficial da União, Brasília, DF, 30 out. 1998b. Disponível em: <http://www. planalto.gov.br/ccivil_03/decreto/D2829.htm>. Acesso em: 24/5/2011.

. Ministério da Educação. Fundo Nacional de Desenvolvimento da Educação. Relatório de atividades do FNDE - 1998. Brasília, DF, 1998a. Disponível em: <http:// www.fnde.gov.br/fnde/institucional/relatorios/relat $\% \mathrm{C} 3 \% \mathrm{~B} 3$ rios-de-atividades?downlo $\mathrm{ad}=3587$ :relatorio-atividades-fnde-1998>. Acesso em: 26/9/2013.

. Decreto $\mathrm{n}^{\circ}$ 3.597, de 12 de setembro de 2000. Promulga Convenção 182 e a Recomendação 190 da Organização Internacional do Trabalho (OIT) sobre a Proibição das Piores Formas de Trabalho Infantil e a Ação Imediata para sua Eliminação, concluídas em Genebra, em 17 de junho de 1999. Diário Oficial da União, Brasília, DF, 13 set. 2000b. Disponível em: <http://www.planalto.gov.br/ccivil_03/decreto/D3597.htm>. Acesso em: 29/11/2011.

. Plano Nacional pela Primeira Infância 2011-2022 - Proposta da Rede Nacional Primeira Infância. Brasília, DF: Rede Nacional Primeira Infância, maio 2010a.

. Ministério da Educação. Fundo Nacional de Desenvolvimento da Educação. Programas - ProInfância. Disponível em: <http://www.fnde.gov.br/programas/proinfancia/proinfancia-apresentacao $>$. Acesso em: 24/5/2011.

COELHO, Maria Francisca Pinheiro; TAPAJÓs, Luziele Maria de Souza; RODRIGUES, Mônica (Orgs.). Políticas sociais para o desenvolvimento: superar a pobreza e promover a inclusão. Brasília, DF: Ministério do Desenvolvimento Social e Combate à Fome; UNESCO, 2010.

ORGANIZAÇÃO DAS NAÇÕES UNIDAS (ONU). Declaração mundial sobre a sobrevivência, a proteção e o desenvolvimento das crianças nos anos 90. Nova York, 1990. Disponível em: <http://www.mp.ma.gov.br/arquivos/COCOM/arquivos/centros_de_apoio/cao_direitos_humanos/direitos_humanos/crianca/decMundial.htm $>$. Acesso em: 13/2/2012.

ORGANIZAÇÃO DAS NAÇÕES UNIDAS PARA A EDUCAÇÃO, A CIÊNCIA E A CULTURA (UNESCO). Representação da Unesco no Brasil. Constituição da Organização das Nações Unidas para a Educação, a Ciência e a Cultura - adotada em Londres, em 16 de novembro de 1.945, emendada pela Conferência Geral nas suas $2^{\mathrm{a}}$, $3^{\mathrm{a}}, 4^{\mathrm{a}}, 5^{\mathrm{a}}, 6^{\mathrm{a}}, 7^{\mathrm{a}}, 8^{\mathrm{a}}, 9^{\mathrm{a}}, 10^{\mathrm{a}}, 12^{\mathrm{a}}, 15^{\mathrm{a}}, 17^{\mathrm{a}}, 19^{\mathrm{a}}, 20^{\mathrm{a}}, 21^{\mathrm{a}}, 24^{\mathrm{a}}, 25^{\mathrm{a}}, 26^{\mathrm{a}}, 27^{\mathrm{a}}, 28^{\mathrm{a}}$ e $29^{\mathrm{a}}$ sessões. Brasília, DF, 2002.

PROGRAMA DAS NAÇÕES UNIDAS PARA O DESENVOLVIMENTO (PNUD). Objetivos de desenvolvimento do milênio. Disponível em: < http://www.pnud.org.br/ odm/>. Acesso em: 13/2/2012. 
REDE NACIONAL PRIMEIRA INFÂNCIA. Plano nacional pela primeira infância - resumido. Brasília, DF, dez. 2010. Disponível em: <http://primeirainfancia.org.br/ wp-content/uploads/PPNI-resumido.pdf>. Acesso em: 27/9/2013.

SERVIÇO NACIONAL DEAPRENDIZAGEM RURAL (SENAR). Programas. Disponível em: <http://www.senar.org.br/programas>. Acesso em: 29/11/2011.

VASCONCELOS, Francisco de Assis Guedes de. Josué de Castro e a Geografia da Fome no Brasil. Cadernos de Saúde Pública, Rio de Janeiro, v. 24, n. 11, p. 2710-2717, nov. 2008. Disponível em: <http://www.scielo.br/pdf/csp/v24n11/27.pdf>. Acesso em: 29/11/2011.

Texto recebido em 22 de março de 2012.

Texto aprovado em 12 de maio de 2013. 